\title{
Breach modelling by overflow with TELEMAC 2D: comparison with large- scale experiments
}

\author{
Christophe Laroche ${ }^{1, a}$, Mathieu Alquier ${ }^{1}$, Fanny Floriani ${ }^{2}$ and Ron Tejral ${ }^{3}$ \\ ${ }^{1}$ Cerema, Direction territorial Méditerranée, 30 avenue Albert Einstein, CS 70499, 13593 Aix en Provence CEDEX 03, France \\ ${ }^{2}$ DREAL Nord Picardie, 56 rue Jules Barni, 80040 Amiens Cedex, France \\ ${ }^{3}$ United States Department of Agriculture - Agricultural Research Service -1301 N Western Rd Stillwater Oklahoma, USA
}

\begin{abstract}
An erosion law has been implemented in TELEMAC 2D to represent the surface erosion process to represent the breach formation of a levee. We focus on homogeneous and earth fill levee to simplify this first implementation. The first part of this study reveals the ability of this method to represent simultaneously both formations of the breach and the scour hole at the rear of the levee. The resistance or no of the levee seems consistent with the resistance of the soil material given by a standard classification. But this first part has showed that the lateral development of the breach cannot be represented. In the second part of this study, a simply widening of the breach method based on continuous surface erosion process, has been implemented. The comparison with large scale experiments which has been made, shows that both dynamics of the breach formation and the width are not correctly estimated with the only one surface erosion process. Further developments have to be done to integrate the headcut erosion process and mass failure as sliding of the sides of the breach or undercutting.
\end{abstract}

\section{Introduction}

To reduce flood risk, embankments are usually used, but history shows that the consequences of embankment failure can be severe. For example, a large part of 66 fatalities and 2,8 billions of Euros occurred during the flooding of the south of France in 1999, 2002 and 2003, could be affected to breaches [1].

Breaching process involves different processes as surface erosion, shear failure, mass failure, head cut erosion, undercutting of the breach sides, sliding of the breach sides. The breaching process also involves the effects of the combination of complex interactions between hydraulic, geometric and soil property effects. For example, the compaction water content, which has been identified as a key factor to assess the embankment resistance, can modify by orders of magnitude the rate of breach formation.

To assess this complexity, a combination of knowledge and skills from these different disciplines is required [2].

This article firstly gives a short presentation of the few possibilities to assess the behaviour of an embankment. Afterwards we detail the guidelines of our methodology to represent the embankment's behaviour during an overflow. Afterwards, we compare our results with two field experiments available in the literature. Finally, we discuss our results and give some outlook of our work.

\section{How define the features of the failure of a levee?}

The historical information of the breaches of a levee system are usually searched in France when a flood risk prevention plan or a levee risk survey must be realized. This kind of information is used to base an argument to define the breach formation scenario. The quantity and the quality of this information are often not sufficient to assess a realistic growth failure in the studied levee segment. To add to this information, we usually use information available on another levee segment. We have so to discuss the locale conditions of both levee segments, such as geometric features, soils properties of the material of both levees and hydraulic solicitations.

To give some help to discuss them, a breaching model, which takes into account the local conditions, can be used. Few tools are available to assess the breach growth by a physically approach. We can find deterministic models and probabilistic models. WinDamB is a model include in the first family which simulates breach formation through headcut development on the douwstream face of the dam, next the advance of the headcut through the crest and into the reservoir and then the widening of the breach [3].

HR Breach is another model in this family, which use simulates breach initiation and formation through

a Corresponding author: Christophe.laroche@cerema.fr, christophe.laroche.job@gmail.com 
surface erosion and which is integrated into bidimensional flow modelling package [4].

In the second family, we can particularly find AREBA model, which is developed to run in less than one second. Thus AREBA allows to assess the effects on the breach formation of the uncertainty of the main parameters which govern the initiation and the growth. In [5] this kind of work has been made to verify the ability of AREBA to simulate correctly the physical processes by running AREBA 500 times with input parameters given by pre-defined uniform distributions.

All of these tools have been developed to simulate the failure of embankments, which can be dams or levees. They can be usefull to assess the range of the main features of the breach, and only HR Breach can be used directly in a flow modelling package. But for levees, the resistance of the foundation could have an influence on the initiation and may be on the formation of the breach. Indeed, the scour hole created on base of the downstream face during the overflowing, changes the geometric features and then can modify the hydraulic conditions and the erosion processes: for example with a greater velocity thus a greater surface erosion, or with bigger slopes for the breach sides which can accelerate by sliding the lateral development of the breach.

\section{The guidelines of our methodology}

The following key issues have been identified to build our methodology:

1) In accordance with an end-user vision, we decide to develop a specific module for breach modelling in a flow modelling package. TELEMAC 2D has been chosen because this is an open source suite model which have been used in the context of very many studies throughout the world as flood risk management plans or dam break studies. TELEMAC 2D simulates free-surface flows in two dimensions of horizontal space. At each point of the mesh, the program calculates the depth of water and the two velocity components. TELEMAC-2D solves the Saint-Venant equations using the finite-element or finite-volume method and a computation mesh of triangular elements. It can perform simulations in transient and permanent conditions (www.opentelemac.org).

Several assumptions incorporated in the SaintVenant equations may not be verify for breach modelling. Particularly, the average channel bed slope must be small and the water pressure must be hydrostatic. In the first time, our enduser vision overrides these questions.

2) In accordance with [2], the erosion of material from breach is represented by an erosion law. Thus the material is represented by its erodibility which depends on the type of material (cohesive or non-cohesive), the soil compaction and moisture content. Partheniades law [6] was chosen as erosion law, which gives the erosion rate $(\varepsilon)$ as a function of effective shear stress $\left(\tau-\tau_{c}\right)$ and a detachment rate coefficient $\left(k_{d}\right)$.

$$
\varepsilon=\mathrm{k}_{\mathrm{d}} *\left(\tau-\tau_{c}\right)
$$

$\varepsilon \quad$ is the erosion rate $(\mathrm{m} / \mathrm{s})$

$k_{d} \quad$ is the erodibility factor (m3/N.s)

$\tau_{c} \quad$ is the shear threshold $(\mathrm{Pa})$

$\tau \quad$ is the shear stress $(\mathrm{Pa})$

Using the Manning formula and the results coming from TELEMAC 2D, it is possible to calculate the shear stress and thereby the erosion rate in each node of the mesh of the model. The shear stress is assessed by strong hypothesis as the using of depth-averaged velocity instead of the bed shear velocity. Moreover, turbulence effects are not taken into account in this approach.

The erosion of a cohesive material is easily represented by this law, but the deposition of the material, downstream the erosion zone cannot be represented.

3) At the beginning of this work, we suppose that we can develop a breach model without predefined breach shape. The erosion can be only due to the velocity of the flow, when it exceeds the effective shear stress. In addition to the breach formation, it is possible to represent simultaneously the scour hole development during the overflow. In the same way, the lateral development of the breach is not correlated with the rate of crest lowering. Thus, the breach formation is only due, in this first step, to the surface erosion coming from the erosion law used.

4) The results of the coupling of a $2 \mathrm{D}$ flow model with a very simple representation of the material and its resistance, are compared with large-scale experiments, available in the literature. It seems obvious that there will be a gap between both and that the model breach proposed here has to be improved. This methodology gives an opportunity to understand the sequence of the main processes involved in the breach initiation and formation and to develop for end-users the most simple and the most explicit tool as possible.

\section{Preliminary applications}

We focus on earth-fill and homogeneous levees. The erodibility classification proposed in 2009 by Wahl [7], and presented in figure 1, is used to qualify the resistance of the levee and its foundation. The resistances of these two entities are considered equal here. 


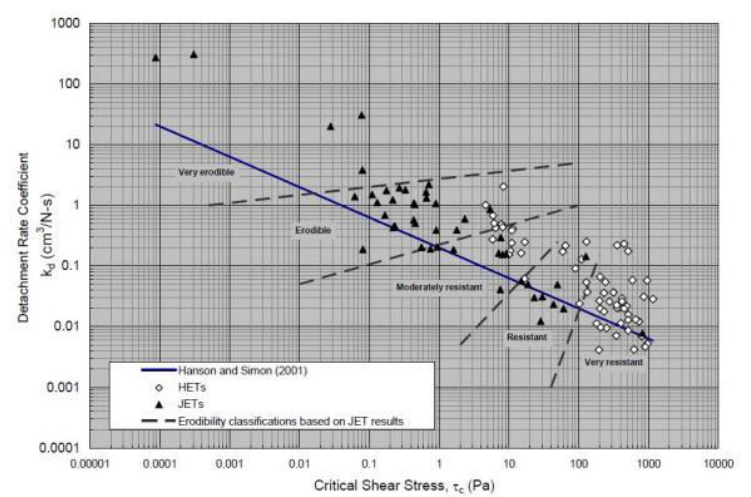

Figure 1. Erodibility classification based on $\mathrm{k}_{\mathrm{d}}$ and $\mathrm{t}_{\mathrm{c}}$ according to [7]

\subsection{Geometry and hydraulic description}

We consider 3 materials with different resistances which are presented in table I. In each case, the resistance of the foundation is considered as equal to the resistance of the embankment.

\begin{tabular}{|l|l|c|c|}
\hline & $\begin{array}{c}\text { Classification of the } \\
\text { resistance material }\end{array}$ & $\begin{array}{c}\mathbf{k}_{\mathbf{d}} \\
\mathrm{m}^{3} / \mathrm{N} . \mathrm{s}\end{array}$ & $\begin{array}{c}\boldsymbol{\tau}_{\mathbf{c}} \\
\mathrm{Pa}\end{array}$ \\
\hline Set 1 & erodible & $10^{-5}$ & 0,1 \\
\hline Set 2 & moderately erodible & $10^{-7}$ & 10 \\
\hline Set $\mathbf{3}$ & resistant & $10^{-8}$ & 50 \\
\hline
\end{tabular}

Table 1. Resistance of the material for all sets tested

We considered a channel with a $0,1 \%$ slope, a trapezoidal section $20 \mathrm{~m}$ wide at the bottom and $26 \mathrm{~m}$ wide at the surface. The levee is $6 \mathrm{~m}$ wide at the crest and $14 \mathrm{~m}$ at the base. It is placed on the left bank, $4 \mathrm{~m}$ back.

To fix the position of the breach, we cut a notch, on the crest of the levee, $20 \mathrm{~cm}$ deep by $18 \mathrm{~m}$ wide.

The size of the mesh is 3 meters in the breach. Then, the mesh size increases gradually to reach 50 meters far from the position of the breach.

A no erodible bedrock is assumed below the bottom of the channel.

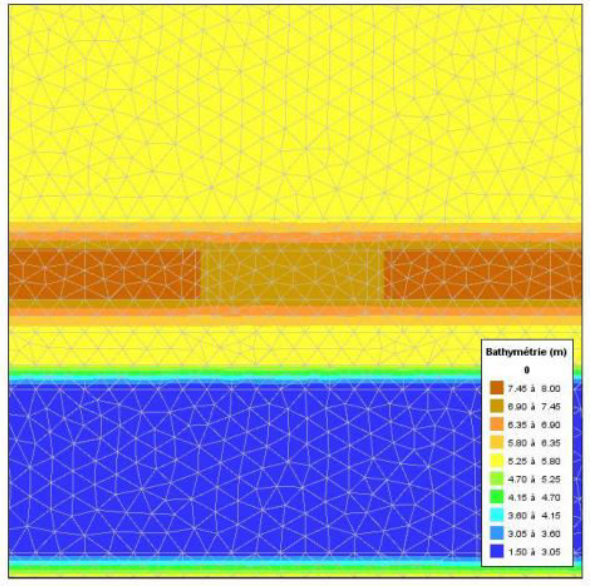

Figure 2. Mesh around the position of the breach

A constant viscosity of $0,005 \mathrm{~m} / \mathrm{s}^{2}$ is used and the Strickler friction coefficient is fixed at $20 \mathrm{~m}^{1 / 3} \mathrm{~s}^{-1}$.

An overflow is simulated by using a trapezoidal hydrograph presented on the figure 3 .

The overflow starts at $\mathrm{t}=1 \mathrm{~h} 30$ minutes when the flow reaches $205 \mathrm{~m}^{3} / \mathrm{s}$ and lasts 3,25 days.

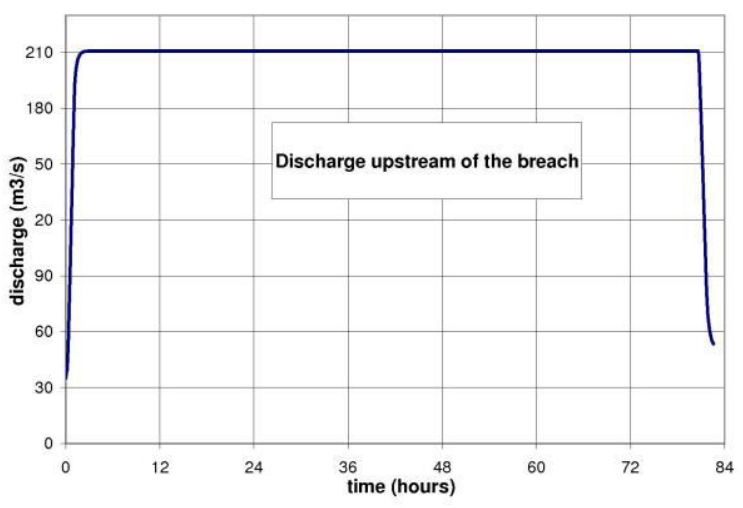

Figure 3. Input hydrograph on the channel

\subsection{Results}

With the more erodible material (set 1), the levee is completely breached about one hour after the beginning of the overflow as we can see in figure 5. Simultaneously as the breach formation, a scour hole is created at the rear of the levee. The figure 5 presents both evolutions of the erosion of the levee and the foundation during the overflow. 


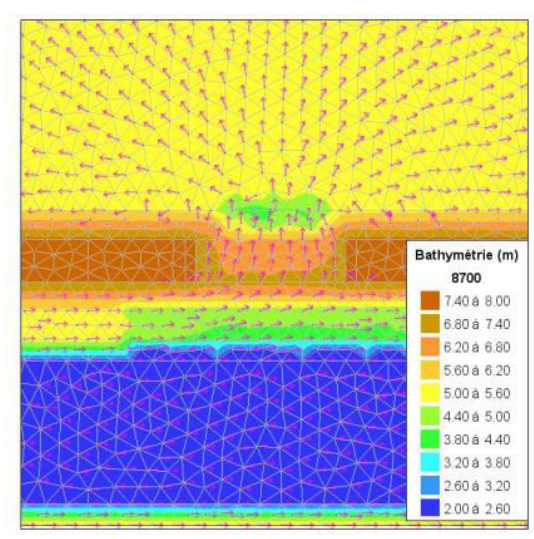

About 50 minutes after the beginning of the overflow

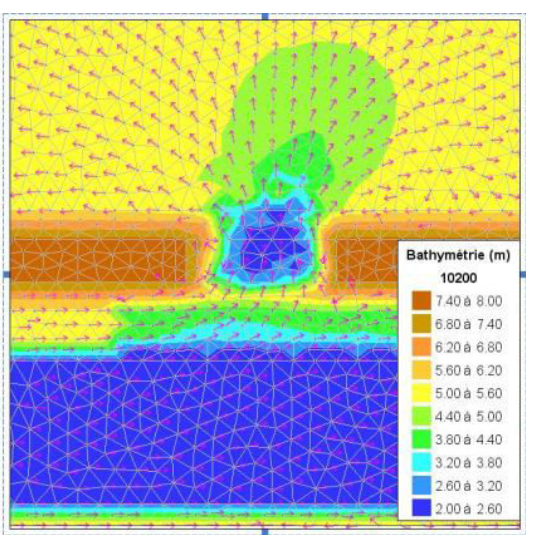

About 1 hour and 15 minutes after the beginning of the overflow

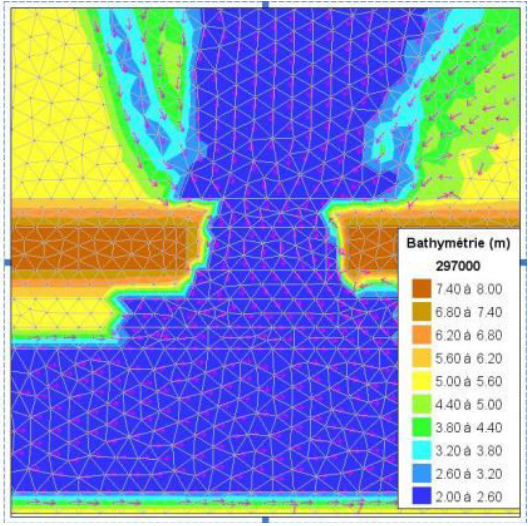

At the end of the simulation

Figure 4. Evolution of the erosion of the embankment and the foundation during the overflow (set 1 ) The velocity field in red is represented with a constant magnitude

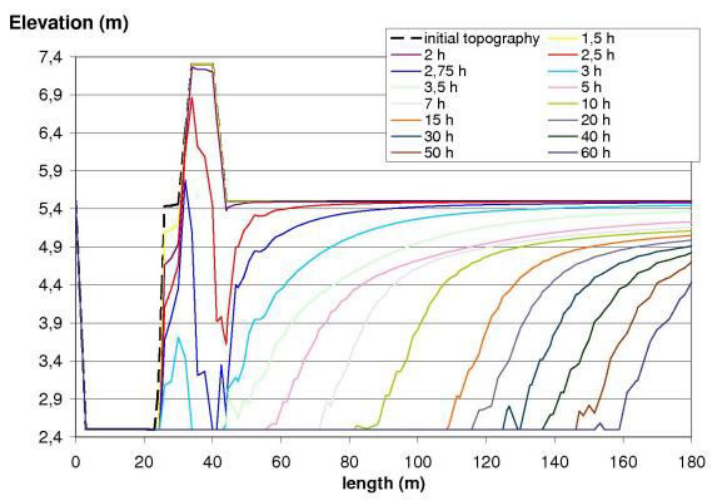

Figure 5. Time evolution of the erosion ( set 1)

As we can see on the figure 6 , the assessment of the volume passing through the breach depends on the taking account of the scour hole.

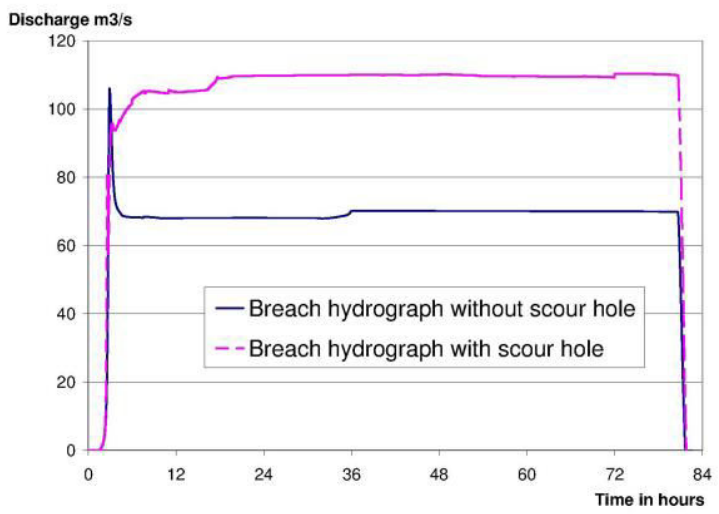

Figure 6. Comparison of breach hydrographs (set 1)

With the moderately erodible material (set 2), the levee resists to an overflow during 3 days despite an erosion of the crest and of the downstream face of the levee, as we can see in figure 7. A very small scour hole is observed.

The more resistant material (set 3) is not eroded despite a 3 days overflow.

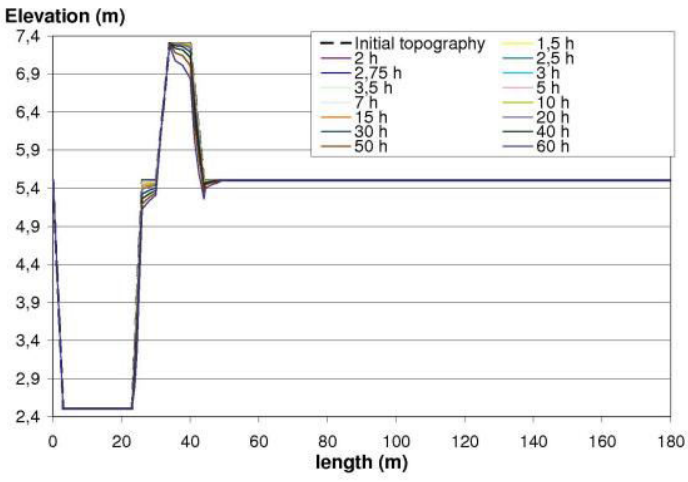

Figure 7. Time evolution of the erosion (set 2)

Because the mesh size has an influence on the velocity value on each node of the mesh, it has an influence on the erosion rate calculated too. To assess this effect, we have made a short test with a 1 meter mesh size in the breach. In this test, all of the erosion rates are accelerated. For example, the erosion rate of the moderately erodible material is almost doubled; Precisions are available in [8]. But for the resistance material levee tested (set 3), the acceleration of the erosion rate does not modify the behavior of the levee with an overflowing during more than 3 days.

Despite an influence of the mesh size identified, the resistance of the levee simulated in this short application of our method seems broadly consistent with the erodibility of the materials proposed in [7] and presented in figure 1.

This method could be seen as a method to represent the breach formation due to surface erosion only. For each case in which erosion is observed, we can see a scour hole of the downstream foot of the levee, which is usually saw in historical breaches. The figure 6 shows that the lateral development of the breach is clearly not represented in this method. 


\section{Comparison with large-scale experiments}

\subsection{Lateral development method}

To represent the lateral development of the breach, we assume to conserve the same process as in the first part of this work: the widening of the breach is assumed given by the flow. This assumption allows to assess the contribution of the continuous surface erosion process given by the flow, in the lateral development of the breach. . Of course this approach will not be sufficient, as described in [9]. Several other processes, as the undercutting and the collapse of the breach sides (mass failure) or the sliding of the breach sides, have a large influence on the lateral development of the breach.

Thus, only the partially wetted elements of the mesh, which have 2 nodes wetted, are considered here. For each wetted node of this kind of element, it is possible to calculate an erosion rate, with the method presented above. The average of these 2 erosion rates is used to define the erosion rate of the wetted base of this element.

All of these erosion rates are vertical movements, and our problem is to convert them into horizontal erosions. To do this, we suppose that the erosion rate of the element can also be applied perpendicularly on the partially wet elements. This assumption is materialized by the red dotted arrow in figure 8 . The horizontal projection of this erosion rate (the green arrow) gives the lateral erosion rate of the partially wet element considered, during the time step $d t$.

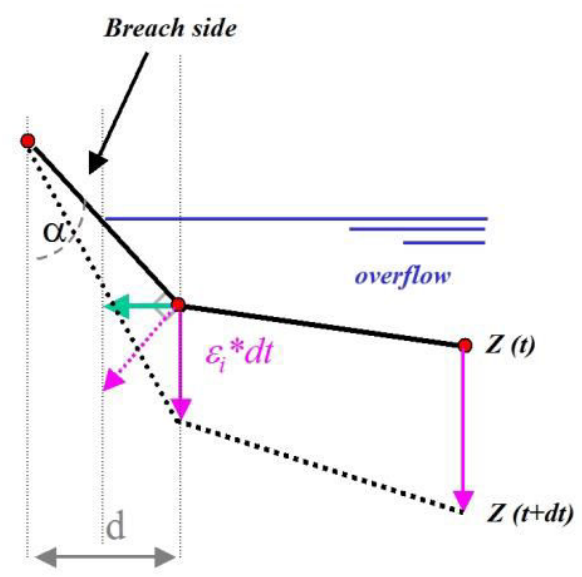

Figure 8. Principle of the lateral development method

This method assumes that the lateral development of the breach depends on the inclinations of the breach sides and the flow velocity on their foot.

For each time step and for each element, the lateral erosion is stored during the simulation. For an element, when the cumulative value is greater than $d$, the elevation of the dry node is setting to the mean altitude of the wetted nodes.

\subsection{Large scale experiments used}

The USDA-ARS dataset used consists of two experiments. Both experiments were performed in the same location, hence the reservoir storage is the same. The embankment was constructed $2,3 \mathrm{~m}$ high and with three test sections with different soils. Each test section have $7,3 \mathrm{~m}$ wide. To fix the position of the breach, a notch $0,46 \mathrm{~m}$ deep by $1,83 \mathrm{~m}$ wide was cut into each test section. All features of these experiments are given in [10] and [11].

As given in table 2, with the erodibility classification proposed by Wahl in [7], the embankment of the first experiment can be considered as a very erodible one. For the second experiment, the embankment can be considered as a resistant one.

\begin{tabular}{|l|c|c|c|}
\hline & $\begin{array}{c}\text { Classification of the } \\
\text { resistance material }\end{array}$ & $\begin{array}{c}\mathbf{k}_{\mathbf{d}} \\
\mathrm{m}^{3} / \mathrm{N} . \mathrm{s}\end{array}$ & $\begin{array}{c}\boldsymbol{\tau}_{\mathbf{c}} \\
\mathrm{Pa}\end{array}$ \\
\hline Experiment 1 & very erodible & $10,3 \cdot 10^{-6}$ & 0,14 \\
\hline Experiment 2 & resistant & $3,9.10^{-8}$ & 15 \\
\hline
\end{tabular}

Table 2. Resistance of the material for the 2 experiments

Four stages have been identified in [10] to describe the overtopping erosion processes in cohesive material: - stage I: rills erosion occur in the downstream face, one or more master rills develop into a cascade of overfalls. In the end of this stage, a large headcut is formed at the downstream crest, with a width of erosion approximately equal to the width of the flow at the downstream crest.

- stage II: the headcut migrates from the downstream to the upstream crest of the embankment. The lateral development of the erosion occurred due to mass wasting of material from the sides of the gully.

- stage III: this stage begins with the lowering of the upstream crest and ends when the entire upstream face is eroded. Then, the breach is completely formed.

- stage IV: this stage represents the widening of the breach due to the emptying of the reservoir.

The figure 9 gives an overview of the timing of an embankment failure using data available for the experiment 1 .

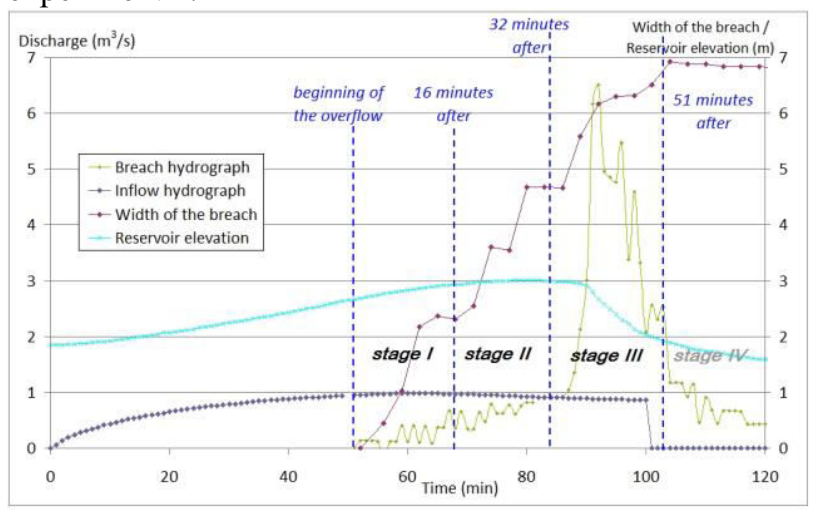

Figure 9. Time lines of observed erosion width, reservoir water surface elevation and hydrographs for experiment 1 
In relation to the sizes of the notch and the embankment, the size mesh is $0,2 \mathrm{~m}$ in the supposed breach zone.

The Strickler friction coefficient is fixed at $25 \mathrm{~m}^{1 / 3} \mathrm{~s}^{-1}$.

A model with a constant viscosity of $0,004 \mathrm{~m}^{2} / \mathrm{s}$ is used.

\subsection{Results}

\subsubsection{Comparison with experiment 2}

In the field experiment 2, despite more than 19 hours of overflow, no breach occurred during the experiment due to the resistance of the soil.

Stage I lasted a little less than 3 hours (164 minutes) and because the upstream crest of the embankment did not be eroded, the stage III did not be reached.

As we can see on figure 10 (b)/(c), the lateral development of the breach occurred during stage II, due to mass wasting of material from the sides of the gully. The final width of the gully is given in [10] and [11] and is about $4,2 \mathrm{~m}$.

Inflow and outflow hydrographs are the same with a constant value of about $1 \mathrm{~m}^{3} / \mathrm{s}$.

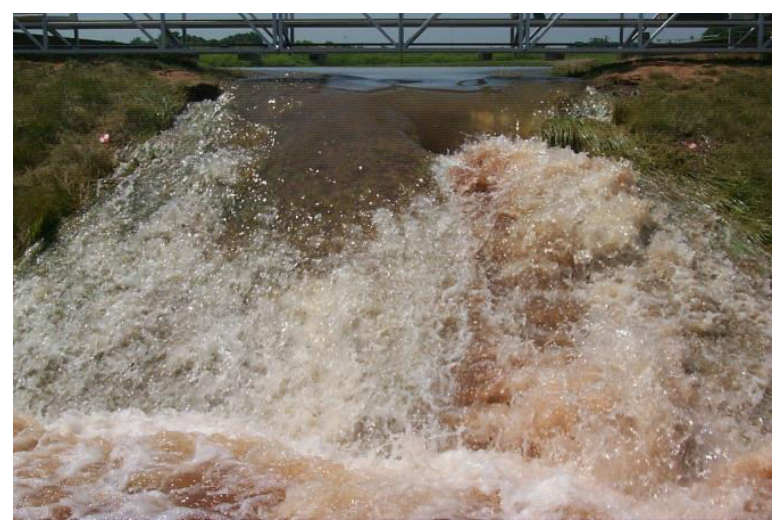

2 hours after the beginning of the overflow (a)

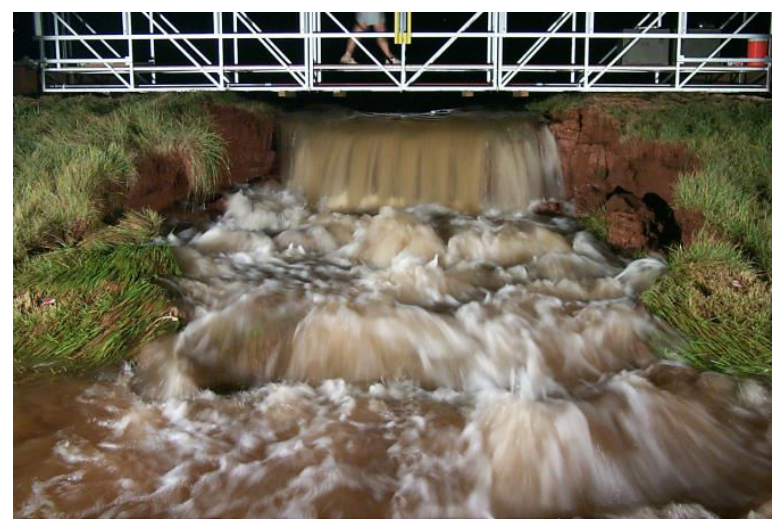

12 hours after the beginning of the overflow $(b)$

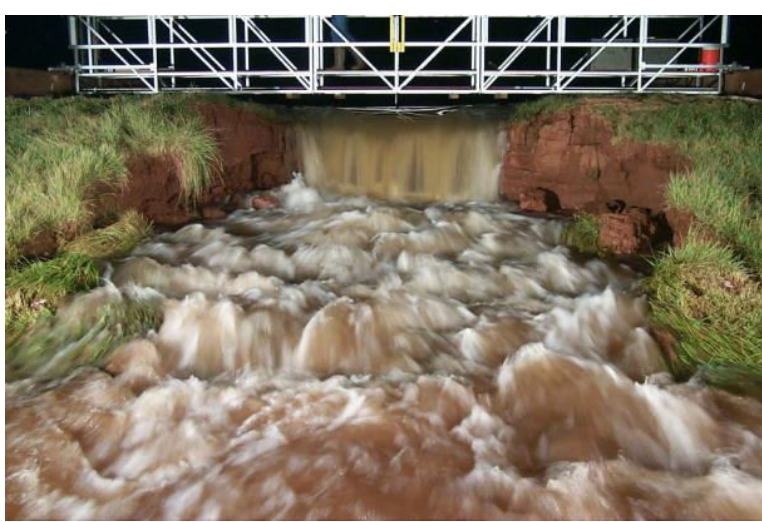

19 hours after the beginning of the overflow (c)

Figure 10. (a)/(b)/(c) ): Time evolution of the breach formation for experiment 2 according to [10]

In our results, we can see in figure 11, a final erosion of the downstream face of the embankment. The maximum erosion depth is $0,46 \mathrm{~m}$ on the foot of the downstream face. Regarding the experiment results, this erosion is very limited. During the stage I, only one rill occurs without overfall and the stage II does not seem to have been reached in our results.

Our results represent only the erosion due to the contact between the material and the flow, which is also called surface erosion process. The soil property effects as headcut process have to be integrated in our method to correctly represent the dynamic of the breach formation. Hence the calculated erosion rate of the embankment is broadly underestimated.

Because the upstream crests are not eroded in our method and in the field experiment, both breach outflow hydrographs are the same.

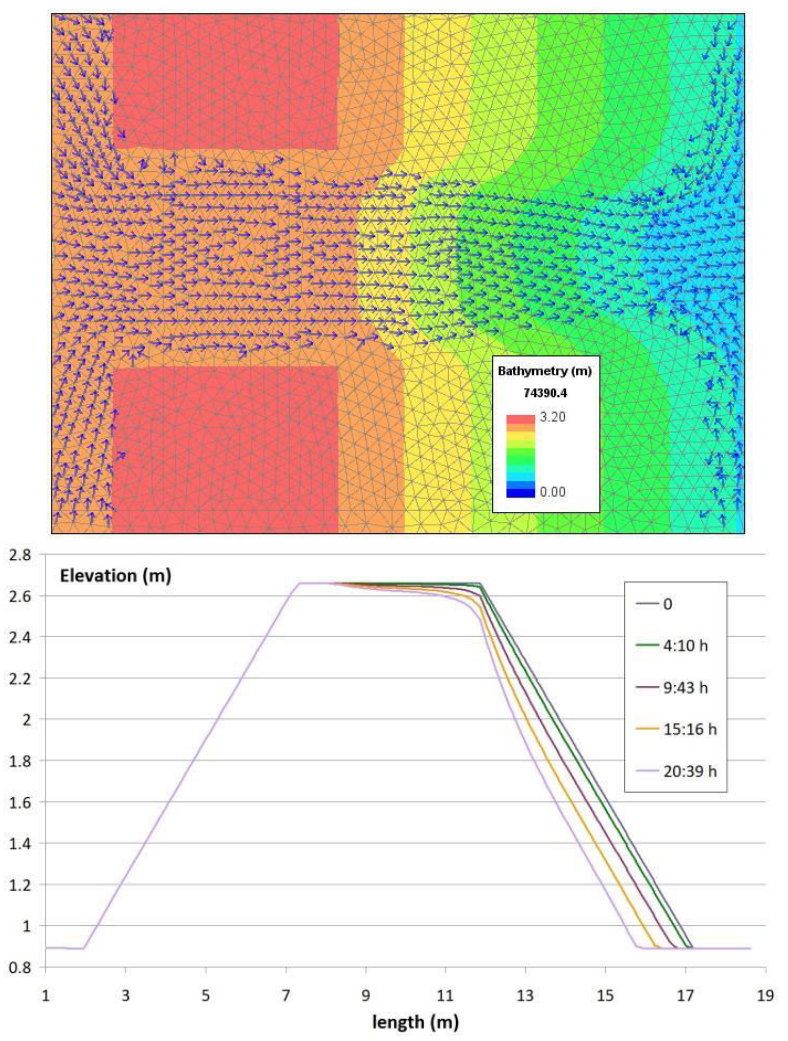

Figure 11. Top view and cross-section results for experiment 2 


\subsubsection{Comparison with experiment 1}

In the field experiment 1 , less than 50 minutes after the beginning of the overflow, the breach was completely formed. In the two first stages of the breach formation, the lateral development of the gully occurred due to soil property effects and also geometric and hydraulic effects. During these two stages, the breach hydrograph increased due to the elevation of the water level in the reservoir, as we can see in figure 9. In the end of stage II, the width of the gully was a little less than 5 meters [10].

The upstream crest of the embankment began to be eroded about 32 minutes after the beginning of the overflow (stage III). During this stage, the lateral development of the breach increased a little more than 2 meters, to reach 7 meters. In the figure 9 we can see that the failure occurred whereas the water elevation in the reservoir has not started to decrease. In the field experiment 1 , the breach hydrograph reached $6 \mathrm{~m}^{3} / \mathrm{s}$. This hydrograph decreased quickly because of the small reservoir size.

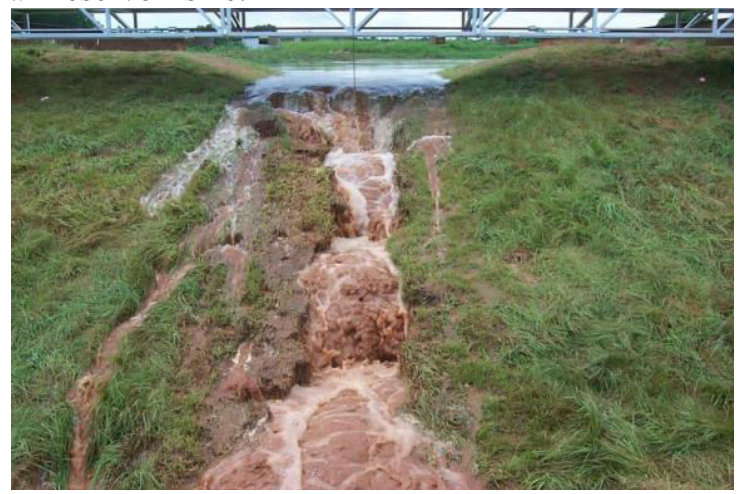

5,5 minutes after the beginning of the overflow (a)

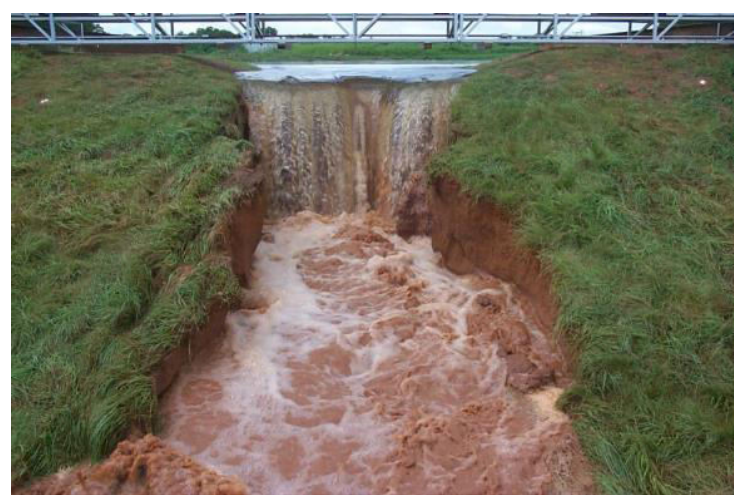

14,5 minutes after the beginning of the overflow $(b)$

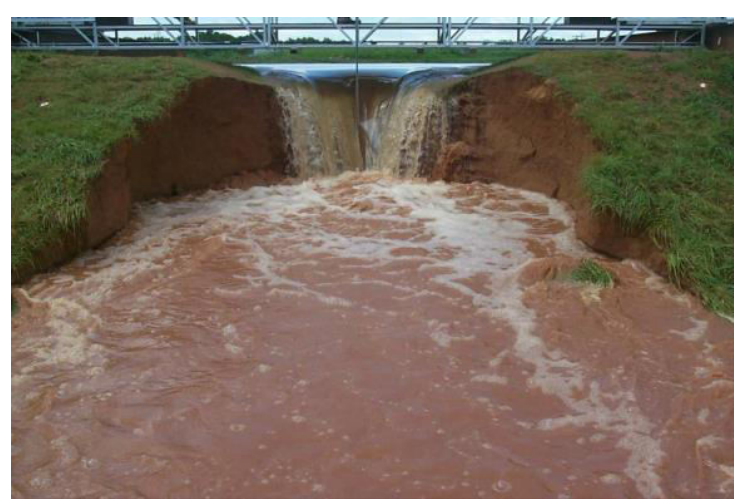

29,5 minutes after the beginning of the overflow (c)

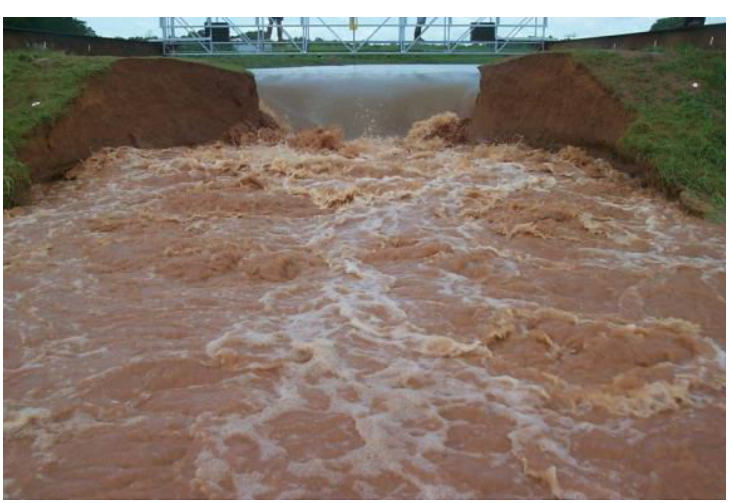

38,5 minutes after the beginning of the overflow $(d)$

Figure 12. (a)/(b)/(c)/(d): Time evolution of the breach formation for experiment 1 according to [10]

In our results, from the beginning of the overflow, an erosion of the embankment is observed on the downstream face as in the field experiment, but also on the crest. This second erosion, which is not observed in the field experiment, comes from the very erodible material used. In our result, velocities are sufficient to erode the crest surface. This difference could be explained by the grass we can see on the embankment in figure 12(a) and which is not represented in our model. The consequence is a greater increasing of outflow discharge in our results, as we can see in figure 13.

In our results, the erosion rate of the downstream face is not as important as in the field experiment. This stage lasts about 24 minutes against 16 minutes in the field experiment. Soil property effects, as headcut, but also mesh size effect, may explain a part of this difference. Due to the very erodible material, the erosion of the upstream crest at the beginning of the overflow produces the increasing of the breach hydrograph in the calculation. Consequently, the water level decreases more rapidly in our results, as we can see in figure 14.

The end of the erosion of crest surface (end of stage II) could be assessed broadly at the same moment that in field experiment. Until this moment, the upstream crest continues to be eroded and the outflow continues to increase gradually.

Due to the erosion of the upstream face since the beginning of the overflow, the stage III is not consistent with the definition.

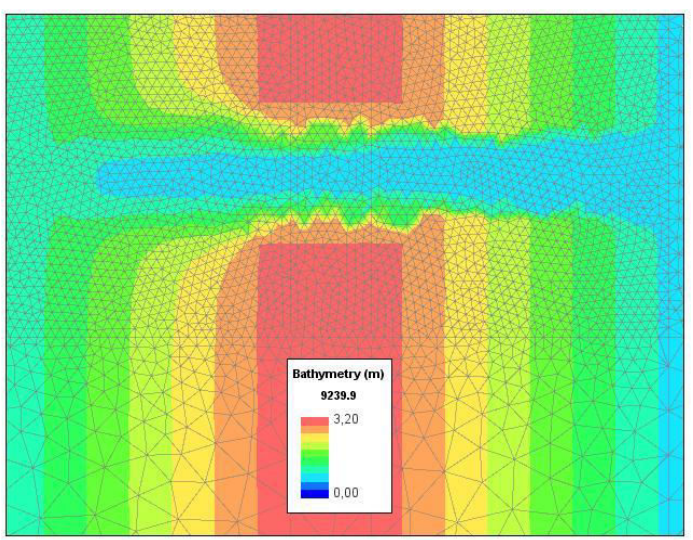

Figure 13. TELEMAC 2D and observed data comparison and top view results for experiment 1 
In the end of the calculation, the upstream face is broadly eroded, but a $0,4 \mathrm{~m}$ high of material remains in our results as we can see in figure 13 .

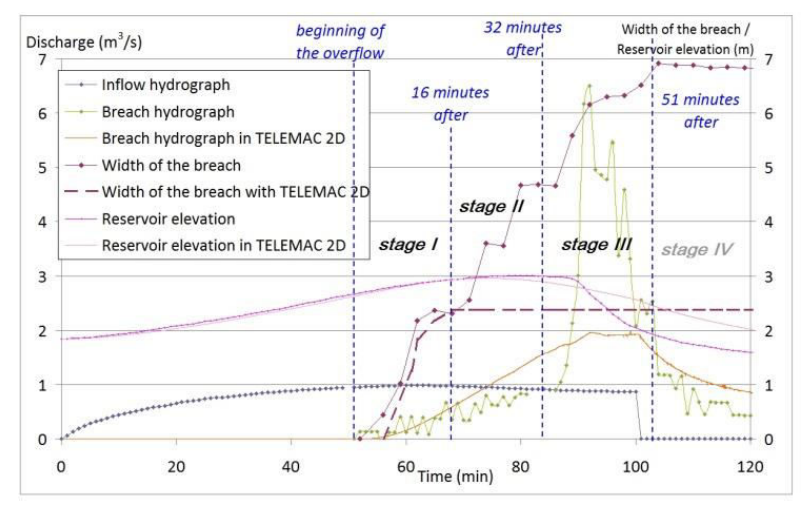

Figure 14. TELEMAC 2D and observed data comparison for experiment 1

In our results, from the beginning of the overflow, the breach hydrograph increase gradually to reach about 2 $\mathrm{m}^{3} / \mathrm{s}$. This dynamic and this peak flow are not consistent with the observations.

The figure 14 presents the evolutions of the breach width from the field experiment and our method. The gap between both is clearly represented. Our method must be improved to have a better assessment of the width of the breach.

\section{Discussions}

The use of an erosion law in TELEMAC 2D gives an opportunity to represent by a surface erosion process, the erosion of a levee due to overflowing. With this continuous erosion process, a breach formation and a score hole at the rear of the levee can be estimated simultaneously.

The results presented here show that the behaviours of the levees are consistent with the resistance of the material given by the classification proposed in [7]. The short test, we have made, seems to show that this first result depends on the mesh size. A larger study of the sensitivity of the mesh to the behaviour of the levee has to be realized to clarify this point.

The comparison with the experiment 2 of USDAARS shows that the breach initiation stage is not underestimated in TELEMAC 2D. The main erosion process of the downstream face of the levee is not only a surface erosion process. The headcut process, which can be sow as a formation of small steps to finally create an only one step, has an important influence on the dynamic of the erosion. This erosion process has been studied and a headcut advance rate has been proposed in [9] and [10]. The efficiency of our method will be improved by using this kind of representation.

The comparison with the experiment 1 of USDAARS shows that the calculated erosion of the crest surface of the levee from the beginning of the overflowing is not visible in the field observations. A short test done to integrate a $10 \mathrm{~cm}$ grass layer in our method confirms the supposed effect of the grass cover on the embankment.

This comparison also shows that the continuous erosion process is not the right process to assess the peak flow sow in the observations. The dynamic of the observed hydrograph, with a peak flow over $6 \mathrm{~m}^{3} / \mathrm{s}$, cannot be simulated with the method used here. In order to have a better approach for this dynamic, we suppose that a very faster erosion process must be taken into account. By multiplying the erosion rate of the material by 10 , it is confirm this point of view. This kind of phenomenon could be due to the modification of the resistance of the core of the levee, for example because of the water content or because of a sliding process of the upstream face of the levee. To finish, the comparison of the evolutions of the breach width, as we can see in figure 13, presents a real gap. Even if the beginnings of the widening could be considered similar, when the downstream face of the levee is completely eroded, the calculated width cannot increase. At this moment, the flow is completely fixed on the gully and without geometric and material property effects, the width of the breach cannot increase. To improve the assessment of the width of the breach and its dynamic, we suppose these kinds of processes can be used:

- A mass failure of the breach side, which can be due to undercutting and collapse of the breach sides,

- A mass failure of the breach side, which can be due to sliding of the sides of the breach,

- A headcut erosion, as we can see on the downstream face of the levee.

\section{Outlooks}

We hope that the methodology used here and the first results will be a good base to develop a specific module in TELEMAC 2D to assess the breach formation. To improve this first implementation in TELEMAC 2D we have to integrate a mechanic approach and the material property effects, as detailed above.

We also hope that the number of experimental cases available to compare with our results will increase in the next years because this confrontation is the best way to improve the knowledge of breaching process and to increase the ability of breach models to approach this complex reality.

\section{Acknowledgements}

The main author would like to thank gratefully:

- The USDA-ARS for sharing and providing the dataset of observations about their large-scale experiments.

- Ron Tejral, for the help and the information given about these observations. 


\section{References}

1. DREAL Languedoc Roussillon (2009). Les digues protègent...mais peuvent rompre

2. Morris M.W.(2009). Breaching Processes: A state of the art review, In FLOODSite project, rep No T06-06-03, HR Wallingford UK.

3. USDA - NRCS (2009). WinDamB : Quick Start Guide. Module for Fam Design and Analysis

4. CIRIA (2013). The International Levee Handbook. Chapter 8, pp 937-942

5. Van Damme M., Morris M.W., Hassan M. (2012). WP4.4 : A new approach to rapid assessment of breach driven embankment failures. Flood Risk Management Research Consortium. Research report SWP4.4.

6. Parthéniades E. (1965). Erosion and deposition of cohesive soils. Journal of the Hydraulic Division, n⿳91, pp 105-139.

7. Wahl T. L., Hanson G. J., Reggazzoni P.L. (2009). Quantifying erodibility of embankment materials for the modelling of Dam breach processes. Proc. of the ASDSO Dam Safety, Hollywood, Florida, 24p.

8. Laroche C, Alquier M. (2013). Implementation of an erosion law in TELEMAC-2D: a way to predict the characteristics of a breach ? Proceedings of the XXth TELEMACMASCARET User Conference. Karlsruhe, BAW, pp 103-107.

9. Hunt S.L., Hanson G.J., Cook K.R., Kadavy K.C. (2005). Breach widening observations from earthen embankment test. American Society of Agricultural Engineers, vol. 48(3) 1115-1120.

10. Hanson G.J., Cook K.R., Hunt S.L. (2005). Physical Modeling of Overtopping Erosion and Breach Formation of Cohesive Embankments. American Society of Agricultural Engineers, vol. 48(5) 1783-1794.

11. Hanson G.J. (2002). Embankment Research in the US. IMPACT Investigation of Extreme Flood. Processes \& Uncertainty, Workshop at HR Wallingford, UK on 16 \& 17 May 2002 